\title{
Formation of Free Radical Products by the Reaction of Dehydro- ascorbic Acid or Ninhydrin with Aromatic Amines
}

\author{
Midori Yano, Tateki Hayashi and Mitsuo NamikI \\ Department of Food Science and Technology, Faculty of Agriculture, \\ Nagoya University, Nagoya 464 \\ Received October 27, 1977
}

\begin{abstract}
Reactions of DHA with aromatic amines in ethanol produced fairly stable esr signals with characteristic hyperfine structures that indicated the presence of the aromatic moiety in the radical molecules. Several intermediates of ninhydrin reactions, i.e., carbinolamines and Schiff bases, were isolated and these two were found to give rise to similar esr signals when subjected to reaction with ascorbic acid. This also provided basis for the elucidation of the structures of the radical species from the reaction of DHA and aromatic amines.
\end{abstract}

Previous papers from this laboratory have shown that characteristic esr signals entirely different from those of melanoidins and other polymeric biological materials ${ }^{1 /}$ are produced in early stages of amino-carbonyl reactions between sugars and amino acids, ${ }^{2)}$ dehydroascorbic acid (DHA) and amino acid ${ }^{37}$ or that between DHA and alkylamines. ${ }^{4}$ Presumed structures of the radical species responsible for the esr signals were proposed for each type of the reactions, based mainly on analysis of the hyperfine structures of the signals and, moreover, some of the possible formation pathways were proposed. ${ }^{4}$ With the aim of obtaining confirmatory evidence for the structure and formation mechanism of the radical products, especially for those of DHA-amine system, free radicals formed by the reaction of ninhydrin with amines were investigated. The structures of two different free radical species formed by the reaction of ninhydrin with primary alkyl amines have been presented in the preceding paper. ${ }^{5}$

This report mainly deals with the radical species produced by the reaction of ninhydrin with aromatic amines, and a tentative reaction pathway was proposed based on the experimental results on several isolated intermediate products. An explanation of the mechanism of radical formation by DHA and aromatic amines was given by analogy to the above.

\section{MATERIALS AND METHODS}

DHA was prepared as previously described. ${ }^{3)}$ Ninhydrin, aromatic amines, ascorbic acid (AsA) and other reagents were of guaranteed grade. Reactions of DHA or ninhydrin with aromatic amines were performed in open Pyrex test tubes with $95 \%$ ethanol as solvent, unless otherwise stated. The concentrations of reactions in this paper refer to those under assumption of completely dissolved states, which usually do not occur until a certain stage of reaction is reached. Authentic samples of 2-hydroxy-2-N-phenylamino-1,3indandione and 1,3-diketohydrindylidene-2-p-hydroxyphenylamine were obtained according to the method of Friedman. ${ }^{\text {) }}$

Tlc was carried out on fluorescent silica gel (Wakogel B-5FM) with benzene-methanol (95:5), or on microcrystalline cellulose (Avicel) with $n$-butanol-ethanolwater $(5: 3: 4)$. Some spots except the visually identified ones in the text refer to those observed under a wide range $(250 \sim 400 \mathrm{~nm}) \mathrm{UV}$ source (PAN UV lamp PUV-1).

IR spectra were measured with a JASCO IR-G spectrophotometer using $\mathrm{KBr}$ pellets, and NMR spectra with a JNM-MH-100 spectrometer. Esr spectra were recorded with a JES-ME-1X ESR spectrometer with samples contained in quartz tubes; splitting constants and $g$ values were determined with potassium peroxylamine disulfonate as a standard.

\section{RESULTS}

\section{Reaction of ninhydrin with aromatic amines}

When a mixture of ninhydrin and aniline (ca. $1 \mathrm{M}$ for each) was heated in a boiling water bath for several minutes, a characteristic hyper- 
fine signal shown in Fig. 1 was detected. This was analyzed as being composed of one proton $(7.9 \mathrm{G})$, one nitrogen $(6.5 \mathrm{G})$, two protons $(2.1 \mathrm{G}, 0-\mathrm{H})$, one proton $(1.2 \mathrm{G}, p-\mathrm{H})$ and two protons $(0.4 \mathrm{G}, \mathrm{m}-\mathrm{H})$. By a similar reaction carried out in $99 \% \mathrm{C}_{2} \mathrm{H}_{5} \mathrm{OD}$, the $7.9 \mathrm{G}$ proton splitting was replaced by a $7.9 \mathrm{G} / 6.514=1.2 \mathrm{G}$. It was then suggested that the $7.9 \mathrm{G}$ proton is attached to the $6.5 \mathrm{G}$ nitrogen nucleus.

Similar reaction of ninhydrin with p-aminophenol gave a spectrum shown in Fig. 2-a, which was resolved into one proton $(7.5 \mathrm{G})$, one nitrogen $(6.6 \mathrm{G})$ and two protons $(2.5 \mathrm{G}$, $o-\mathrm{H})$. Similar reaction in DMSO gave a spectrum almost identical with that in $95 \%$ ethanol, except that more finely split spectrum

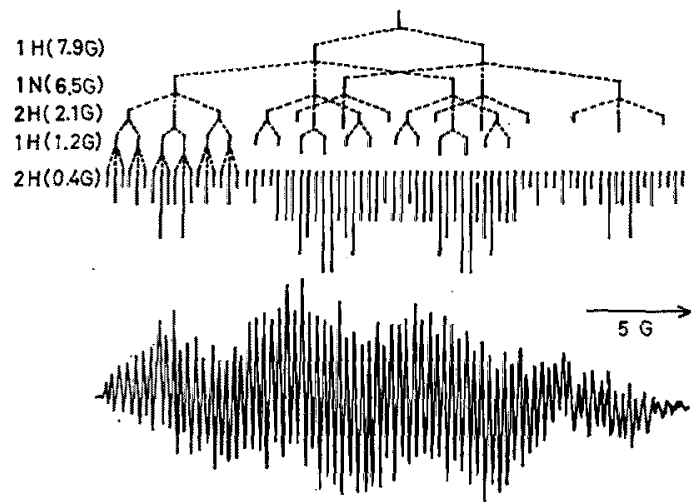

FIG. 1. ESR Spectrum of the Free Radical Produced by the Reaction of Ninhydrin with Aniline in $95 \%$ EtOH.

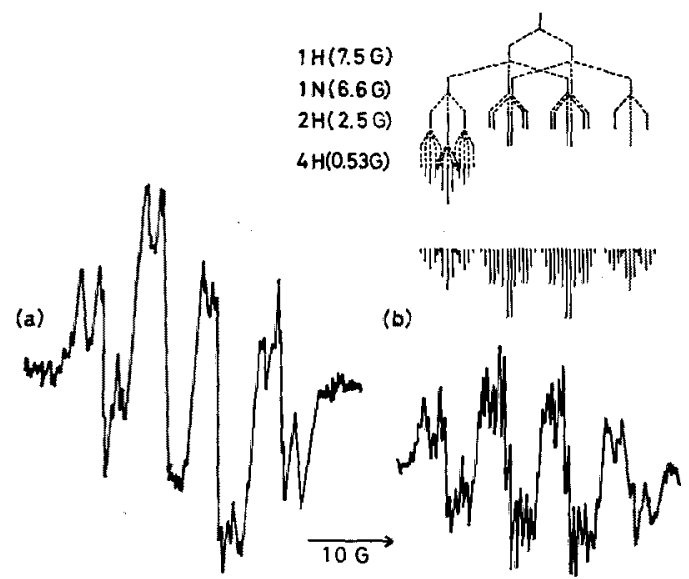

FIG. 2. ESR Spectra of the Free Radicals Produced by the Reaction of Ninhydrin with $p$-Aminophenol, (a) in $95 \% \mathrm{EtOH}$, (b) in DMSO. of quintet $(0.53 \mathrm{G}, 4 \mathrm{H})$ appeared as shown in Fig. 2-b. This might be due to the two $\mathrm{m}$ protons on benzene nucleus and to two of the four protons of indandione nucleus.

With 2,6-xylidine or 2,4,6-trimethylaniline, the signal detected was a quartet line composed of one nitrogen and one proton, with splittings almost equivalent with each other $(7.2 \mathrm{G})$, as shown in Fig. 3. With 2,3- or 2,4-xylidines, quartet signals of $7.1 \mathrm{G}$ were obtained, less clearly defined for the latter. Table I shows these results.
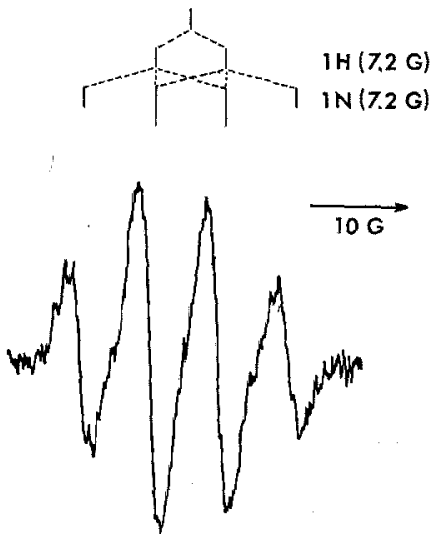

Fig. 3. ESR Spectrum of the Free Radical Produced by the Reaction of Ninhydrin with 2,4,6-Trimethylaniline in $95 \% \mathrm{EtOH}$.

\section{Isolation of reaction intermediates from the reac-} tion mixture of ninhydrin with aromatic amines

Some of the reaction intermediates of ninhydrin with aromatic amines that appeared as discrete spots on tlc were isolated from the reaction mixture. With $p$-aminophenol, 2,4xylidine and 2,3-xylidine, their corresponding Schiff bases, and, with aniline, a carbinolamine were isolated. They are designated as S-I, $\mathrm{S}-\mathrm{II}, \mathrm{S}-\mathrm{III}$ and $\mathrm{C}-\mathrm{I}$ respectively. Among them C-I and S-I were previously isolated and identified by Friedman from the reaction mixture of aqueous solutions. ${ }^{6)}$ While S-II and S-III were newly obtained by us.

\section{2-Hydroxy-2-N-phenylamino-1,3-indandione $(C-I)$}

Ninhydrin $(1.3 \mathrm{M})$ and aniline $(1.5 \mathrm{M})$ in $95 \%$ 
Table I. ESR Spectral Parameters of the Free Radicals Produced by the Reaction of Ninhydrin with Aromatic Amines

\begin{tabular}{|c|c|c|c|c|c|c|c|}
\hline \multirow{2}{*}{ Amines } & \multirow{2}{*}{$a^{N}(G)$} & \multirow{2}{*}{$\mathrm{a}_{\mathrm{NH}}^{\mathrm{H}}(\mathrm{G})$} & \multicolumn{3}{|c|}{$\mathrm{a}^{\mathrm{B}}(\mathrm{G})$} & \multirow{2}{*}{$\begin{array}{l}\text { Indan- } \\
\text { dione }\end{array}$} & \multirow{2}{*}{$g$ value } \\
\hline & & & $o-\mathrm{H}$ & $m-\mathrm{H}$ & $p-\mathrm{H}$ & & \\
\hline Aniline & 6.5 & 7.9 & $2.1(2)$ & $0.4(2)$ & $1.2(1)$ & & 2.0038 \\
\hline $\mathrm{C}-\mathrm{I}^{a}$, reduced with AsA & 6.5 & 7.9 & $2.1(2)$ & $0.4(2)$ & $1.2(1)$ & & 2.0038 \\
\hline$p$-Aminophenol in EtOH & 6.6 & 7.5 & $2.5(2)$ & & & & \\
\hline in DMSO & 6.6 & 7.5 & $2.5(2)$ & $0.53(2)$ & & $0.53(2)$ & \\
\hline S-I ${ }^{a}$, reduced with AsA & 6.6 & 7.5 & $2.5(2)$ & $0.53(2)$ & & $0.53(2)$ & 2.0043 \\
\hline 2,4-Xylidine & & & \multicolumn{2}{|c|}{ ambiguous } & & & \\
\hline S-II ${ }^{a}$, reduced with AsA & 7.0 & 7.0 & & & & & \\
\hline 2,3-Xylidine & 7.1 & 7.1 & & & & & \\
\hline S-III ${ }^{a}$, reduced with AsA & 7.1 & 7.1 & & & & & \\
\hline 2,6-Xylidine & 7.2 & 7.2 & & & & & \\
\hline 2,6-Xylidine $+\mathrm{H}_{2} \mathrm{O}$ & 7.1 & 7.1 & & & & & \\
\hline 2,4,6-Trimethylaniline & 7.2 & 7.2 & & & & & \\
\hline
\end{tabular}

a As to C-I, S-I, S-II and S-III, refer to Table II.

Table II. Analytical Data on Ninhydrin Derivatives

\begin{tabular}{|c|c|c|c|c|c|c|c|c|}
\hline \multirow{2}{*}{ Compound } & \multirow{2}{*}{$\operatorname{mp}\left({ }^{\circ} \mathrm{C}\right)$} & \multirow{2}{*}{ Formula } & \multicolumn{3}{|c|}{ Analyses $(\%)$} & \multirow{2}{*}{\multicolumn{3}{|c|}{$\begin{array}{c}\text { Infrared spectra } \\
\left(\mathrm{cm}^{-1}\right)\end{array}$}} \\
\hline & & & & Calcd. & Found & & & \\
\hline \multirow[t]{3}{*}{$\mathrm{C}-\mathrm{I}^{a}$} & $94 \sim 95$ & $\mathrm{C}_{15} \mathrm{H}_{11} \mathrm{NO}_{3}$ & $\mathrm{C}$ & 71.14 & 70.35 & 3318 & 3408 & $(\mathrm{OH}, \mathrm{NH})$ \\
\hline & $(92 \sim 93)^{c}$ & & $\mathbf{H}$ & 4.38 & 4.41 & 1708 & 1748 & $(\mathrm{C}=\mathrm{O})$ \\
\hline & & & $\mathrm{N}$ & 5.53 & 5.44 & & & \\
\hline \multirow[t]{3}{*}{$\mathrm{S}-\mathrm{I}^{b}$} & $228 \sim 230$ & $\mathrm{C}_{15} \mathrm{H}_{\theta} \mathrm{NO}_{3}$ & $\mathrm{C}$ & 71.71 & 70.37 & 3160 & 3400 & $(\mathrm{OH})$ \\
\hline & $(230 \sim 232)^{\circ}$ & & $\mathbf{H}$ & 3.61 & 3.72 & 1730 & 1680 & $(\mathrm{C}=\mathrm{O})$ \\
\hline & & & $\mathbf{N}$ & 5.60 & 5.40 & & & \\
\hline \multirow[t]{3}{*}{$\mathbf{S}-\mathbf{I I}^{b}$} & $194 \sim 196$ & $\mathrm{C}_{17} \mathrm{H}_{13} \mathrm{NO}_{2}$ & $\mathrm{C}$ & 77.55 & 77.19 & 2900 & 2950 & $\left(\mathrm{CH}_{3}\right)$ \\
\hline & & & $\mathbf{H}$ & 4.98 & 5.24 & 1700 & 1730 & $(\mathrm{C}=\mathrm{O})$ \\
\hline & & & $N$ & 5.32 & 5.18 & & & \\
\hline \multirow[t]{3}{*}{$\mathbf{S}-\mathrm{III}^{b}$} & $193 \sim 195$ & $\mathrm{C}_{17} \mathrm{H}_{13} \mathrm{NO}_{2}$ & $\mathrm{C}$ & 77.55 & 77.21 & 2940 & 2980 & $\left(\mathrm{CH}_{3}\right)$ \\
\hline & & & $\mathbf{H}$ & 4.98 & 5.22 & 1705 & 1738 & $(\mathrm{C}=\mathrm{O})$ \\
\hline & & & $\mathbf{N}$ & 5.32 & 5.21 & & & \\
\hline
\end{tabular}

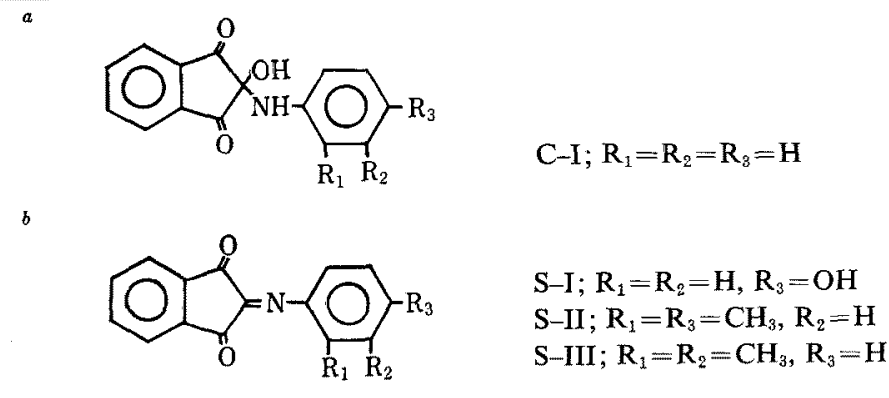

c Reference 6)

ethanol were allowed to react in a boiling water bath for a few minutes. Yellow precipitate that separated after standing for a short time at room temperature, was identified as 2-hydro$\mathrm{xy}-2-\mathrm{N}$-phenylamino-1,3-indandione, from the comparison of $\mathrm{mp}, \mathrm{NMR}, \mathrm{IR}$, elemental analyses and $R f$ value with that of the authentic specimen. Analytical results are shown in Tables II and III. 
Table III. Nuclear Magnetic Resonance Data on Ninhydrin Derivatives

${ }^{1} \mathrm{H}-\mathrm{NMR}$ (100 MHz, Internal reference TMS)

\begin{tabular}{|c|c|c|}
\hline Compound & Solvent & Chemical shifts $(\tau)$ \\
\hline \multirow[t]{7}{*}{$\mathrm{C}-\mathrm{I}$} & $\mathrm{CDCl}_{3}$ & $1.92(4 \mathrm{H}, \mathrm{m}$, indandione $\mathrm{H})$ \\
\hline & & $2.69(5 \mathrm{H}, \mathrm{m}$, benzene $\mathrm{H})$ \\
\hline & $\mathrm{CD}_{3} \mathrm{OD}$ & $2.01(4 \mathrm{H}, \mathrm{s}$, indandione $\mathrm{H})$ \\
\hline & & $2.92(2 \mathrm{H}, \mathrm{q}, \mathrm{m}-\mathrm{H}, \mathrm{Jmp} 8.0$ \\
\hline & & $\mathrm{Hz}$ with Jom $6.6 \mathrm{~Hz}$ ) \\
\hline & & $3.29(3 \mathrm{H}, \mathrm{t}, \mathrm{p}-\mathrm{H}, \operatorname{Imp} 8.0 \mathrm{~Hz}$ \\
\hline & & and $\mathrm{d}, \mathrm{o}-\mathrm{H}, \operatorname{Jom} 6.6 \mathrm{~Hz}$ ) \\
\hline \multirow[t]{3}{*}{ S-I } & $\mathrm{CDCl}_{3}$ & $1.96(4 \mathrm{H}, \mathrm{m}$, indandione $\mathrm{H})$ \\
\hline & & $2.44(2 \mathrm{H}, \mathrm{d}, \mathrm{m}-\mathrm{H}, \mathrm{J} \circ \mathrm{m} 9.0 \mathrm{~Hz})$ \\
\hline & & $3.14(2 \mathrm{H}, \mathrm{d}, \mathrm{o}-\mathrm{H}, \mathrm{Jom} 9.0 \mathrm{~Hz})$ \\
\hline \multirow[t]{5}{*}{ S-II } & DMSO- $d_{6}$ & $2.09(4 \mathrm{H}, \mathrm{m}$, indandione $\mathrm{H})$ \\
\hline & & $2.93(1 \mathrm{H}, \mathrm{s}$, benzene $\mathrm{H})$ \\
\hline & & $3.07(2 \mathrm{H}, \mathrm{s}$, benzene $\mathrm{H})$ \\
\hline & & $7.71\left(3 \mathrm{H}, \mathrm{s}, \mathrm{CH}_{3}\right)$ \\
\hline & & $7.85\left(3 \mathrm{H}, \mathrm{s}, \mathrm{CH}_{3}\right)$ \\
\hline \multirow[t]{5}{*}{ S-III } & DMSO- $\mathrm{d}_{\mathrm{\theta}}$ & $1.98(4 \mathrm{H}, \mathrm{m}$, indandione $\mathrm{H})$ \\
\hline & & $2.99(2 \mathrm{H}, \mathrm{d}$, benzene $\mathrm{H})$ \\
\hline & & $3.20(1 \mathrm{H}, \mathrm{m}$, benzene $\mathrm{H})$ \\
\hline & & $7.71\left(3 \mathrm{H}, \mathrm{s}, \mathrm{CH}_{3}\right)$ \\
\hline & & $7.92\left(3 \mathrm{H}, \mathrm{s}, \mathrm{CH}_{3}\right)$ \\
\hline
\end{tabular}

1,3-Diketohydrindylidene-2-p-hydroxyphenylamine $(S-I)$

From the mixture of ninhydrin $(1 \mathrm{M})$ with $p$ aminophenol $(1 \mathrm{M})$ in $95 \%$ ethanol heated in a boiling water bath for about $5 \mathrm{~min}$ and stored at room temperature, red brown precipitate separated out. The recrystallized product (hot $\mathrm{MeOH}$ ) was identified as 1,3-diketohydrindylidene - 2 - $p$-hydroxyphenylamine, on the basis of analytical data in Tables II and III (Yield 67\%).

\section{I,3-Diketohydrindylidene-2-[2,4-dimethylphenyl-} amine $(S-I I)$ and 1,3-diketohydrindylidene-2[2,3-dimethylphenylamine $](S-I I I)$

In the case of 2,3-xylidine or 2,4-xylidine, after reaction with ninhydrin ( $1 \mathrm{M}$ for each) in $95 \%$ ethanol for a few minutes in a boiling water bath and standing the mixture overnight at $5^{\circ} \mathrm{C}$ deposited purple (2,3-xylidine), or greenish black $(2,4$-xylidine) product. Analyses on recrystallized products from hot $\mathrm{MeOH}$ (Tables II and III) indicated the products to be Schiff bases, 1,3-diketohydrindylidene-2-[2,3-dimethyl phenylamine] (Yield 26\%) and 1,3-diketohydrindylidene-2-[2,4-dimethylphenylamine].
Formation of free radicals by reduction of ninhydrin derivatives

As soon as powdered AsA ( $0.4 \mathrm{M})$ was added to the solution of C-I in $95 \%$ ethanol $(0.4 \mathrm{M})$, the solution immediately gave an intense esr signal, which steadily increased for about two hours and then decreased gradually. The hyperfine structure of the signal was found identical with that detected during the reaction of ninhydrin with aniline in ethanol (Fig. 1). Tlc of the reaction mixture of C-I before and after the addition of AsA showed absence of either ninhydrin or aniline, which eliminated the possibility of the production of the radical species from these compounds, which might have by chance contaminated the preparation of $\mathrm{C}-\mathrm{I}$ or have been produced by decomposition of $\mathrm{C}-\mathrm{I}$ during the reaction with AsA. The free radical was therefore without doubt produced by the reaction of AsA on C-I. In DMSO medium, however, no esr signal was observed by a similar reaction. This point will be discussed later.

With S-I, to its suspension in ethanol, an appropriate amount of AsA was added in powder form, and the solution was subjected to esr spectrometry. Immediately after the addition of AsA, a strong signal was detected and then decreased gradually. Its hyperfine structure was identical with that detected by the reaction of ninhydrin with $p$-aminophenol in DMSO, rather than that obtained in $95 \%$ ethanol. The absence of ninhydrin or $p$-aminophenol in the reaction mixture was confirmed on tic before and after the reaction.

Similar reaction of S-II or S-III with AsA in $95 \%$ ethanol or DMSO also produced intense free radical signals, whose hyperfine structure was identical with that detected by the reaction of ninhydrin with corresponding amines in $95 \%$ ethanol.

\section{Reaction of $D H A$ with aromatic amines}

When a mixture of DHA and aniline (1 M for each) was heated in a boiling water bath, its yellow coloration first developed changed to green to red within a few minutes, and then gradually to dark brown. Similar color changes 


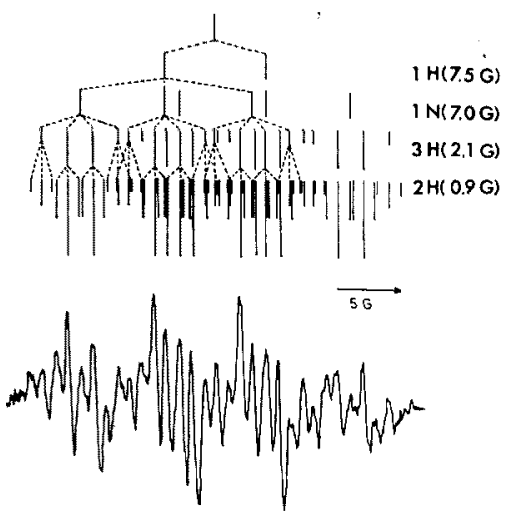

FIG. 4. ESR Spectrum of the Free Radical Produced by the Reaction of DHA with Aniline in $95 \%$ EtOH.

were observed with other aromatic amines, 2,4xylidine, 2,6-xylidine, 2,4,6-trimethylaniline or $p$-aminophenol. In all cases, development of characteristic esr signal was observed within a few minutes after heating. Figure 4 shows the esr spectrum obtained by the reaction of aniline with DHA, whose hyperfine structure can be attributed to one proton $(7.5 \mathrm{G})$, one nitrogen $(7.0 \mathrm{G})$, three protons $(2.1 \mathrm{G}, o-\mathrm{H}$ and $p-\mathrm{H})$ and two protons $(0.9 \mathrm{G}, m-\mathrm{H})$. When DHA was allowed to react with aniline in $99 \%$ $\mathrm{C}_{2} \mathrm{H}_{5} \mathrm{OD}$, the spectrum was a triplet $(\mathrm{ca} .7 .0 \mathrm{G})$ with multiplet splittings $(1.2 \mathrm{G})$, indicating that the proton of $7.5 \mathrm{G}$ should be attached to the

(a)

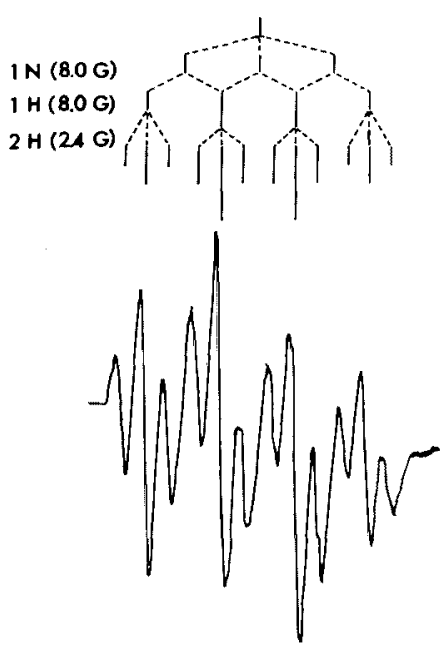

nitrogen of $7.0 \mathrm{G}$. Addition of a small portion of water to the reaction mixture resulted in the change of the spectrum, i.e., quartet signal in ethanol changed to a triplet, which was attributed to one nitrogen $(7.7 \mathrm{G})$, three protons $(1.9 \mathrm{G}, o-\mathrm{H}$ and $p-\mathrm{H})$ and two protons $(0.96 \mathrm{G}$, $m-\mathrm{H})$.

With $p$-aminophenol, the signal obtained showed splittings due to one proton $(8.0 \mathrm{G})$, one nitrogen $(8.0 \mathrm{G})$ and two equivalent protons $(2.4 \mathrm{G}, o-\mathrm{H})$ (Fig. 5-a). Further, addition of water to the reaction mixture, however, changed it to the signal that can be assigned to one nitrogen $(8.2 \mathrm{G})$, two protons $(2.0 \mathrm{G}$, $o-\mathrm{H}$ ), and two protons $(0.6 \mathrm{G}, m-\mathrm{H})$ (Fig. 5-b). Although mechanism of this change is not yet known, it is likely that the addition of water changed an $-\dot{\mathrm{N}} \mathrm{H}$ - radical to an $-\dot{\mathrm{N}}$ - radical. This was taken as an evidence in considering the structure of the radical products.

In the case of 2,6-xylidine or 2,4,6-trimethylaniline, only a quartet signal of $8.1 \mathrm{G}$ was initially detected. With further heating it decreased with simultaneous growth of a triplet signal of $8.4 \mathrm{G}$. By addition of water to the reaction mixture, the spectrum composed of a quartet and a triplet (Fig. 6-a) was changed to a triplet signal (Fig. 6-b), which can be resolved into a triplet $(\mathrm{N}, 8.6 \mathrm{G})$ with multiplet

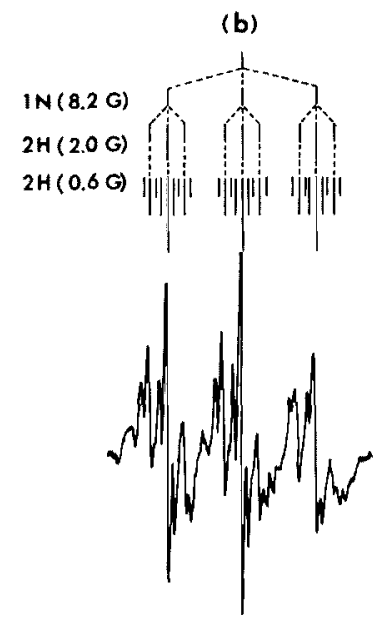

FIG. 5. ESR Spectra of the Free Radicals Produced by the Reaction of DHA with $p$-Aminophenol in $95 \%$ EtOH. (a) reaction mixture; (b) water was added to (a). 


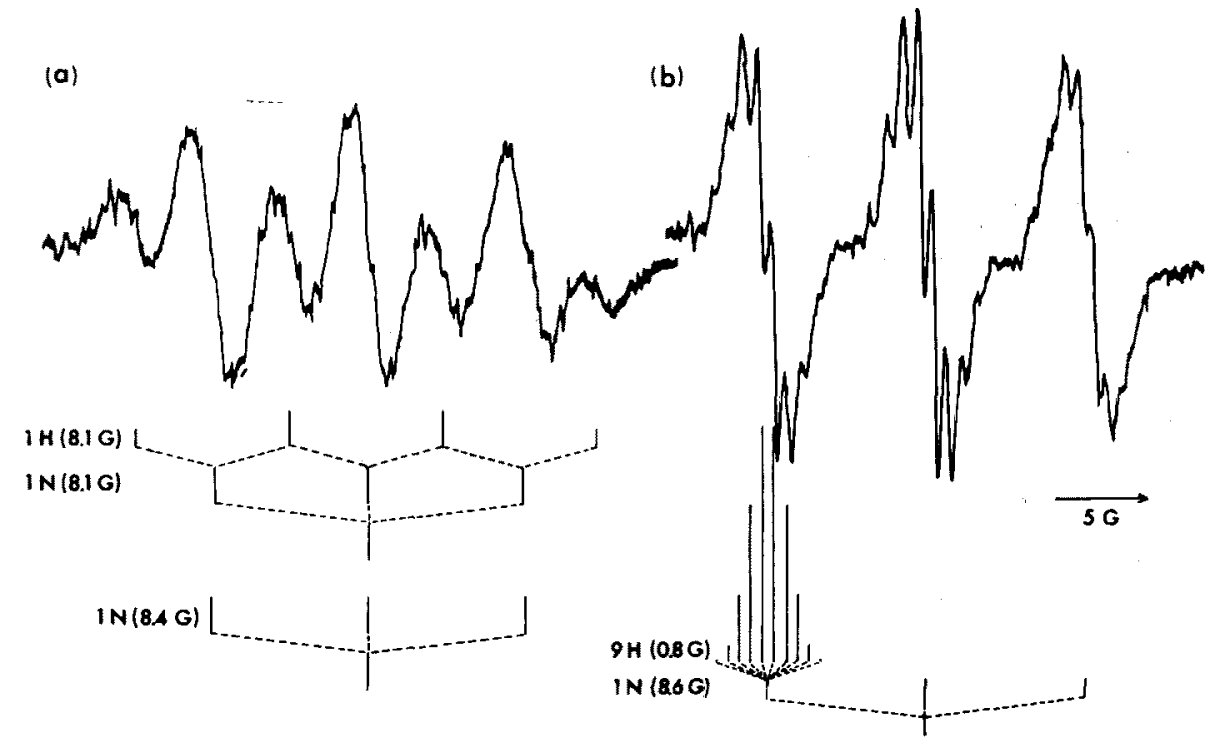

FIG. 6. ESR Spectra of the Free Radicals Produced by the Reaction of DHA with 2,4,6-Trimethylaniline in $95 \% \mathrm{EtOH}$.

(a) reaction mixture; (b) water was added to (a).

(a)

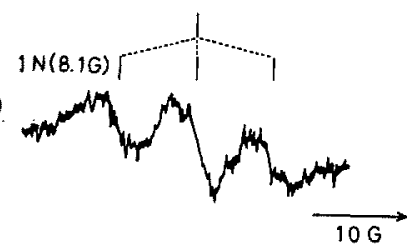

(b)

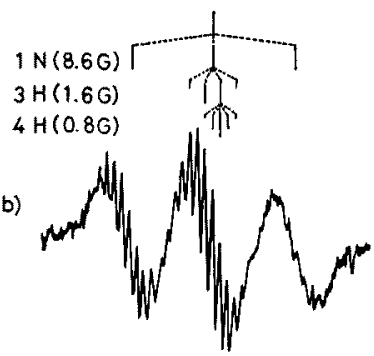

FIG. 7. ESR Spectra of the Free Radicals Produced by the Reaction of DHA with 2,4-Xylidine in $95 \%$ $\mathrm{EtOH}$.

(a) reaction mixture; (b) water was added to (a).

splittings $(0.82 \mathrm{G})$.

On the other hand, the reaction of DHA with 2,4-xylidine or 2,3-xylidine gave the spectrum composed of $c a .8 \mathrm{G}$ due to one nitrogen as shown in Fig. 7. In these cases, addition of water to the reaction mixture only resulted in more finely split signals. Namely, the triplet signal of 2,4-xylidine was further split into 11 lines of ca. $0.8 \mathrm{G}$, which might be attributed to three protons $\left(1.6 \mathrm{G}, p-\mathrm{CH}_{3}\right)$ and four protons $\left(0.8 \mathrm{G}, o-\mathrm{CH}_{3}\right.$ and $\left.o-\mathrm{H}\right)$. In the case of 2,3xylidine, 9 lines of $c a .0 .8 \mathrm{G}$ probably due to one proton $(2.4 \mathrm{G}, p-\mathrm{H})$, one proton $(1.6 \mathrm{G}$, $o-\mathrm{H})$ and three protons $\left(0.8 \mathrm{G}, o-\mathrm{CH}_{3}\right)$, became apparent. These were also utilized to elucidate the details of the structure of the radical products. The results are summarized in Table IV.

Tlc of the reaction mixture of ninhydrin or DHA with p-aminophenol

A mixture of ninhydrin and $p$-aminophenol ( $1 \mathrm{M}$ for each) in $95 \%$ ethanol heated about $5 \mathrm{~min}$ in a boiling water bath showed the chromatogram (Wakogel B-5FM, benzene$\mathrm{MeOH}, 95: 5)$ illustrated in Fig. 8, where the main spot of $R f$ value 0.22 was colored purple. The product isolated from this spot was confirmed to be S-I, by comparison with authentic sample. No radical product could be detected in any scraped-off parts of the chromatogram probably due to its labileness. Addition of AsA on ethanol extract of the part corresponding to $\mathrm{S}-\mathrm{I}$ produced an intense esr signal, but 
Table IV. ESR Spectral. Parameters of the Free Radicals Produced by THE REACTION OF DHA WITH AROMATIC AMINES

\begin{tabular}{|c|c|c|c|c|c|c|}
\hline \multirow{2}{*}{ Amines } & \multirow{2}{*}{$a^{N}(G)$} & \multirow{2}{*}{$a_{N H}^{H}(G)$} & \multicolumn{3}{|c|}{$a^{\mathrm{H}}(\mathrm{G})$} & \multirow{2}{*}{$g$ value } \\
\hline & & & $o-\mathbf{H}$ & $m-\mathrm{H}$ & $p-\mathrm{H}$ & \\
\hline Aniline & 7.0 & 7.5 & $2.1(2 \mathrm{H})$ & $0.9(2 \mathrm{H})$ & $2.1(1 \mathrm{H})$ & 2.0037 \\
\hline in EtOD & 7.0 & & \multicolumn{3}{|c|}{ ca. 1.2 (multiplet) } & \\
\hline 2,6-Xylidine $\begin{array}{l}\text { Quartet } \\
\text { Triplet }\end{array}$ & $\begin{array}{l}8.1 \\
8.4\end{array}$ & 8.1 & & & & \\
\hline $\begin{array}{l}\text { 2,6-Xylidine }+\mathrm{H}_{2} \mathrm{O} \\
\text { 2,4,6-Trimethylaniline }\end{array}$ & 8.6 & & $0.82\left(2 \mathrm{CH}_{3}\right)$ & & $0.82(1 \mathrm{H})$ & \\
\hline $\begin{array}{l}\text { QQuartet } \\
\text { Triplet }\end{array}$ & $\begin{array}{l}8.1 \\
8.4\end{array}$ & 8.1 & & & & $\begin{array}{l}2.0041 \\
2.0040\end{array}$ \\
\hline 2,4,6-Trimethylaniline $+\mathrm{H}_{2} \mathrm{O}$ & 8.6 & & $0.82\left(2 \mathrm{CH}_{3}\right)$ & & $0.82\left(\mathrm{CH}_{3}\right)$ & 2.0041 \\
\hline$p$-Aminophenol & 8.0 & 8.0 & $2.4(2 \mathrm{H})$ & & & 2.0041 \\
\hline$p$-Aminophenol $+\mathrm{H}_{2} \mathrm{O}$ & 8.2 & & $2.0(2 \mathrm{H})$ & $0.6(2 \mathrm{H})$ & & 2.0039 \\
\hline 2,4-Xylidine & 8.1 & & & & & \\
\hline 2,4-Xylidine $+\mathrm{H}_{2} \mathrm{O}$ & 8.6 & & $\left\{\begin{array}{l}0.8\left(\mathrm{CH}_{3}\right) \\
0.8(1 \mathrm{H})\end{array}\right.$ & & 1. $6\left(\mathrm{CH}_{3}\right)$ & \\
\hline 2,3-Xylidine & 8.0 & & & & & \\
\hline 2,3-Xylidine $+\mathrm{H}_{2} \mathrm{O}$ & 8.5 & & $\left\{\begin{array}{l}0.8\left(\mathrm{CH}_{3}\right) \\
1.6(1 \mathrm{H})\end{array}\right.$ & & $2.4(1 \mathrm{H})$ & \\
\hline
\end{tabular}

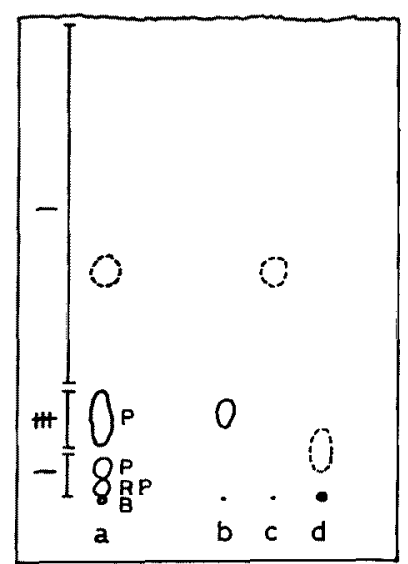

FIG. 8. Thin-layer Chromatogram of the Reaction Mixture of Ninhydrin with $p$-Aminophenol in $95 \%$ EtOH, Developed on Wakogel B-5FM with Benzene$\mathrm{MeOH}(95: 5)$ as solvent.
(a) reaction mixture;
(b) S-I;
(c) ninhydrin;
(d) $p$ - aminophenol.
$O$, colored spots; $Q$, spots observed under wide range. UV lamp: P, purple; RP, ted purple; B, brown. ,+- : Free radical was developed by addition of AsA on the ethanol extract.

not from any other part. Thus S-I alone is believed to be the product that can produce free radicals when reduced by an unknown reducing agent formed in the reaction mixture. Similar results were obtained by tic on Avicel
( $n$-BuOH-EtOH-water, $5: 3: 4$ ), though $R f$ values were different.

Reaction mixture of DHA with p-aminophenol developed with benzene- $\mathrm{MeOH}$ on Wakogel B-5FM plate revealed several products showing as brown, pink, yellow and red. However, neither radical product nor radical precursors could be detected from any part of the chromatogram.

\section{DISCUSSION}

The fact that the action of AsA on intermediate products of the reaction of ninhydrin with aromatic amines produced intense esr signals suggests radical products with structures closely related to these intermediates. General scheme of the pathways of the reaction of ninhydrin with aryl- as well as alkylamines ${ }^{5)}$ may be represented as in Fig. 9, where $R$ denotes aryl or alkyl groups. The representative structures proposed, which probably are in resonance with each other, are consistent with the explanation of the hyperfine structures of the esr signals.

When Schiff base (S-I) was reduced with AsA, the amount of the radical was maximum immediately after addition of AsA and hereafter decreased. On the other hand, with 


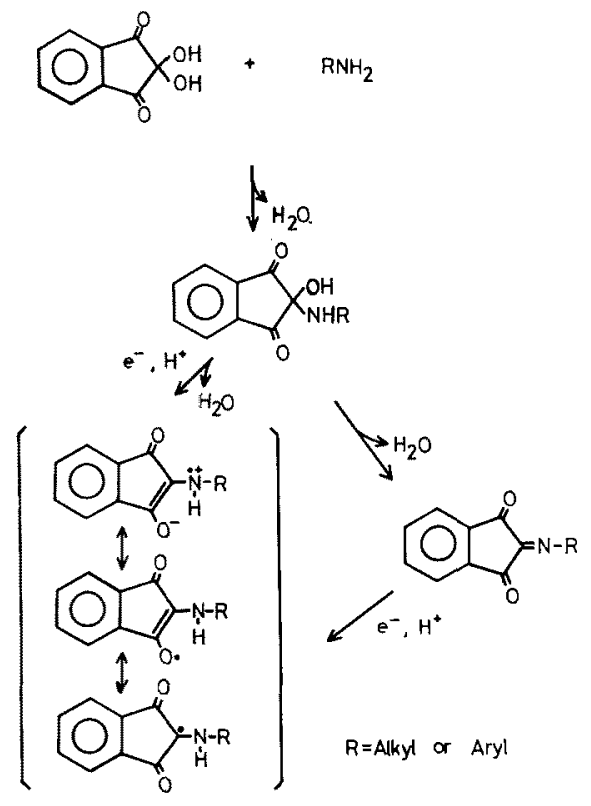

FIG. 9. Possible Formation Mechanism of the Free Radicals by the Reaction of Ninhydrin with Amines.

carbinolamine $(\mathrm{C}-\mathrm{I})$ and AsA, the esr signal continued to increase for about two hours and then decreased gradually. This may indicate that the intermediate which is directly reduced by AsA to produce free radicals may not be the carbinolamine but the Schiff base. This seems to be also supported from the fact that, in DMSO, reduction of the Schiff bases, but not that of carbinolamines, produced intense signals. However, since the amine residues of the carbinolamines and Schiff bases were not identical in this experiment, this is not yet conclusive.

Since neither amine nor ninhydrin reduces the intermediates to produce radical species, the identity of the substance that acts as the reductant during the reaction is at large and is currently under continued study.

In the case of the reaction of DHA with aromatic amines, the radical products formed may be classified into two; one containing an -NH- group (with aniline, 2,6-xylidine, 2,4,6trimethylaniline or $p$-aminophenol) and the other, an - $\mathrm{N}$ - group (with 2,3-xylidine or 2,4xylidine). The hyperfine structure of the former showed the presence of $-\mathrm{NH}$ - group and an aryl group residue, and it changed to that of

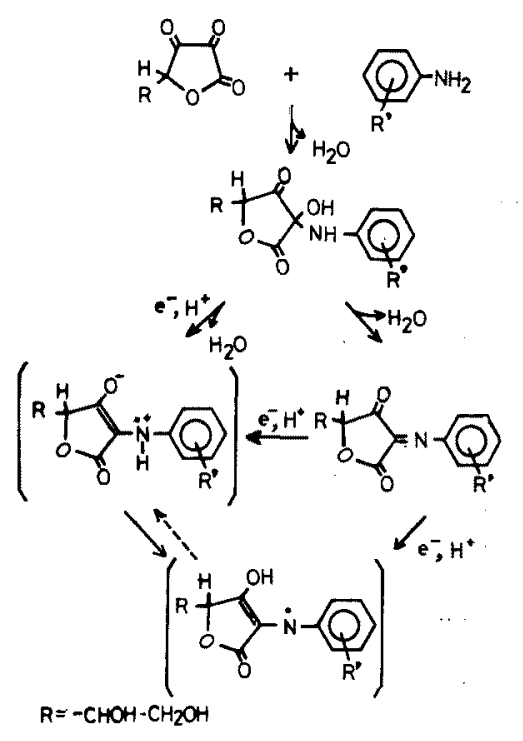

Frg. 10. Possible Formation Mechanism of the Free Radicals by the Reaction of DHA with Aromatic Amines.

$-\dot{\mathrm{N}}$ - radical with the addition of water. Assuming that the structure of the $-\stackrel{-}{N}^{+} H$ radical is of the same type as that of radical products produced by the reaction of ninhydrin with aromatic amines (Fig. 9), the conversion of $-\stackrel{+}{\mathrm{N}} \mathrm{H}$ - radical to $-\dot{\mathrm{N}}$ - radical may easily be explained by proton transfer by interaction with water. The apparent stability of the DHA-aromatic amine radical species, that is large enough to permit detection in situ, seems not very different from that of the ninhydrinaromatic amine species, and that, in contrast to the DHA-alkylamine radical species, ${ }^{4)}$ they are not detectable after separation by tlc.

It may be reasonable to consider that radical products formed by the reaction of DHA with aromatic amines have the structures as shown in Fig. 10, which is composed of one unit of DHA and one unit of the aromatic amine, as in the case of ninhydrin. It is reasonable to assume that the absence of substituted groups at the $o$-positions favors the formation of - ${ }^{+} H-$ radical, as with aniline or $p$-aminophenol. When only one of the o-positions was substituted, the product of $-\dot{\mathrm{N}}$ - radical was dominant as with 2,3-xylidine or 2,4- 
xylidine and, when both of the o-positions were substituted, both types of the product were detected as with 2,6-xylidine or 2,4,6trimethylaniline. This is a working hypothesis at the present stage and needs confirmation and justification.

Acknowledgement. The authors wish to thank Dr. Keiichi Tsuji of the Institute of Physical and Chemical Research for valuable discussions.

\section{REFERENCES}

1) H. Mitsuda, K. Yasumoto and K. Yokoyama,
Agric. Biol. Chem., 29, 751 (1965).

2) M. Namiki, T. Hayashi and S. Kawakishi, ibid., 37, 2935 (1973); T. Hayashi and M. Namiki, J. Agric. Food Chem., 23, 487 (1975); T. Hayashi, Y. Ohta and M. Namiki, ibid., 25, 1282 (1977).

3) M. Namiki, M. Yano and T. Hayashi, Chem. Lett., 1974, 125; M. Yano, T. Hayashi and M. Namiki, ibid., 1974, 1193; M. Yano T. Hayashi and M. Namiki, J. Agric. Food Chem., 24, 815 (1976).

4) M. Yano, T. Hayashi and M. Namiki, Agric. Biol. Chem., 40, 1209 (1976).

5) T. Hayashi, T. Hirata, M. Yano and M. Namiki, ibid., 42, 83 (1978).

6) M. Friedman, Can. J. Chem., 45, 2271 (1967). 